\title{
Effects of ageing and exogenous melatonin on pituitary responsiveness to $\mathrm{GnRH}$ in rats
}

\author{
E. Diaz ${ }^{1}$, D. Pazo $^{2}$, A. I. Esquifino ${ }^{2}$ and B. Diaz ${ }^{1}$ \\ ${ }^{1}$ Dpto Biología Funcional. Area Fisiología, Fac. Medicina, Universidad de Oviedo, Oviedo; and \\ ${ }^{2}$ Dpto Bioquímica y Biología Molecular III, Fac. Medicina, Universidad Complutense, Madrid, Spain
}

\begin{abstract}
The effect of age and melatonin on the activity of the neuroendocrine reproductive system was studied in young cyclic (3-5 months-old), and old acyclic (23-25 monthold) female rats. Pituitary responsiveness to a bolus of GnRH (50 ng per $100 \mathrm{~g}$ body weight) was assessed at both reproductive stages in control and melatonin-treated (150 $\mu \mathrm{g}$ melatonin per $100 \mathrm{~g}$ body weight each day for 1 month) groups. After this experiment, female rats were treated for another month to study the influence of ageing and melatonin on the reproductive axis. Plasma LH, FSH, prolactin, oestradiol and progesterone were measured. A positive LH response to GnRH was observed in both control groups (cyclic and acyclic). However, a response of greater magnitude was observed in old acyclic rats. Melatonin treatment reduced this increased response in acyclic rats and produced a pituitary responsiveness similar to that of young cyclic rats. FSH secretion was independent of GnRH administration in all groups, indicating desynchronization between LH and FSH secretion in response to GnRH in young animals and during senescence. No effect on prolactin was observed. Significantly higher LH $\left(3009.11 \pm 1275.08 \mathrm{pg} \mathrm{m}^{-1} ; P<0.05\right)$ and FSH concentrations (5879.28 \pm $\left.1631.68 \mathrm{pg} \mathrm{ml}^{-1} ; P<0.01\right)$ were seen in acyclic control rats. After melatonin treatment, $\mathrm{LH}\left(811.11 \pm 89.71 \mathrm{pg} \mathrm{ml}^{-1}\right)$ and FSH concentrations $\left(2070 \pm 301.62 \mathrm{pg} \mathrm{ml}^{-1}\right)$ decreased to amounts similar to those observed in young cyclic rats. However, plasma concentrations of oestradiol and progesterone were not reduced. In conclusion, the results of the present study indicate that, during ageing, the effect of melatonin is exerted primarily at the hypothalamo-pituitary axis rather than on the ovary. Melatonin restored the basal concentrations of pituitary hormones and pituitary responsiveness to similar values to those observed in young rats.
\end{abstract}

\section{Introduction}

Different factors are involved in the decline of the reproductive system with age. A decrease in ovarian function, as indicated by a reduced number of ovarian follicles and an associated increase in ovarian resistance to gonadotrophins, has been reported (Navot et al., 1994; Hofmann et al., 1995). The role of the hypothalamo-pituitary axis during the decline of reproductive function remains uncertain. Attenuated preovulatory LH surges related to a decrease in LH pulse amplitude with no change in pulse frequency have been found in female rats during reproductive ageing. This finding indicates that a deficient GnRH drive or reduced responsiveness to the GnRH signal, rather than altered timing of the signal, accounts for the agerelated decline in reproductive function as reflected by an attenuated pro-oestrous LH surge in middle-aged rats (Matt et al., 1998). Studies in young and middle-aged female rats have indicated that reduced pituitary responsiveness to

Received 1 September 1999
GnRH may contribute to the delayed and attenuated prooestrous LH surge that precedes reproductive senescence (Smith et al., 1982). Brito et al. (1994) concluded that a decrease in pituitary $\mathrm{LH}$ responsiveness to $\mathrm{GnRH}$ is only apparent in middle-aged rats that display attenuated prooestrous LH surges.

Ageing of the female reproductive system in rats is marked by discrete stages in the disappearance of regular oestrous cyclicity. Transition to acyclicity is characterized by increased LH pulse duration but decreased amplitude. Changes in pulse generator function may play a role in the age-related transition to acyclicity (Scarbrough and Wise, 1990).

Melatonin has been found to inhibit ageing processes (Pierpaoli et al., 1997; Oaknin-Bendahan et al., 1995; Rasmussen et al., 1999) and its secretion is reduced in senescence (Waldhauser and Steger, 1986; Reiter, 1992). Evidence of hypothalamic melatonin receptor sites (Zisapel et al., 1987) and changes consistent with inhibition of GnRH release after hypothalamic melatonin implants (Glass and Knotts, 1987) have led to the hypothesis that melatonin modulates GnRH 
release. Melatonin administration to aged female rats induced an $18 \%$ increase in the concentration of mRNA encoding $\mathrm{GnRH}$, completely reversing the effect of ageing (Li et al., 1997).

In the present study, the influence of melatonin treatment on pituitary responsiveness to $\mathrm{GnRH}$ and other reproductive hormones in female rats was investigated.

\section{Materials and Methods}

Young (3-month-old) $(n=40)$ and old (23-month-old) female Wistar rats $(n=38)$ from the authors' colony were used. Animals were housed under $12 \mathrm{~h}$ light: $12 \mathrm{~h}$ dark cycles (lights on at 08:00 h) at a temperature of approximately $23^{\circ} \mathrm{C}$. Standard rat chow and tap water were available ad libitum. The sexual cycle of the rats was checked by vaginal smears taken between 10:00 and 11:30 h for 15 days, to select rats showing 4-5 days repetitive oestrous cycles. Vaginal smears were also obtained from 23-month-old rats to determine their acyclicity. None of the aged rats showed 'repetitive oestrous cycles', instead they showed persistent oestrous (PE) $(20.53 \%)$ or dioestrous phases (PD) $(79.47 \%)$. These rats were then assigned to the following groups according to their reproductive status and treatment regimen: cyclic control $(n=18)$, cyclic melatonin-treated $(n=22)$, acyclic control $(n=18)$ and acyclic melatonin-treated $(n=20)$.

\section{Melatonin treatment}

Large doses ( $3 \mathrm{mg} \mathrm{kg}^{-1}$ body weight, administered s.c.) have been used to investigate the effects of melatonin on young and old (24-month-old) albino rats (Gorni et al., 1993), without adverse side-effects. In the present study, doses of $150 \mu \mathrm{g}$ melatonin per $100 \mathrm{~g}$ body weight were used. Melatonin (M-5250, Sigma Chemical Co., St Louis, MO) was dissolved in a small volume of absolute ethanol $(0.02 \mathrm{ml})$ and diluted in $0.9 \% \mathrm{NaCl}$ to a dose of $150 \mu \mathrm{g}$ per $100 \mathrm{~g}$ body weight. Melatonin injections were administered s.c. to cyclic and acyclic rats at the end of the light phase, between 18:30 and 19:00 $\mathrm{h}$ for $1 \mathrm{month}$. Control animals received a placebo solution (absolute ethanol in $0.9 \% \mathrm{NaCl}$ ). After this treatment, the rats were submitted to a GnRH test. After the $\mathrm{GnRH}$ test, melatonin or placebo treatment continued for another month to detect any change in the reproductive hormones during ageing.

\section{Pituitary responsiveness to $G n R H$}

The responsiveness to GnRH was tested between 16:00 and $18.00 \mathrm{~h}$ in cyclic 4-month-old rats during the dioestrous phase of the sexual cycle and in acyclic 24-month-old rats that had been treated with melatonin or placebo for 1 month. After a basal blood sample had been taken, the animals were given an i.v. bolus injection of $50 \mathrm{ng} \mathrm{GnRH}$ per $100 \mathrm{~g}$ body weight (Sigma Chemical Co.), diluted in saline. Injected volumes ranged from 0.05 to $0.1 \mathrm{ml}$. Additional blood samples were obtained at 15, 30, 60 and $90 \mathrm{~min}$ after the $\mathrm{GnRH}$ injection. One millilitre blood samples were obtained by jugular venepuncture under light ether anaesthesia. After each blood extraction, the cut performed on the skin was sutured. Immediately after blood sampling, each rat received its own red blood cells suspended in $0.9 \%$ saline to avoid anaemia. Blood samples were centrifuged at $700 \mathrm{~g}$ for $10 \mathrm{~min}$ and plasma was stored at $-20^{\circ} \mathrm{C}$ until assayed for $\mathrm{LH}, \mathrm{FSH}$ and prolactin.

\section{Plasma concentrations of gonadotrophins, prolactin, oestradiol, and progesterone in cyclic and acyclic rats}

Cyclic rats were decapitated at the end of the treatment period at the next dioestrus and blood samples were collected and processed as described above. Blood samples were obtained from 23-month-old acyclic rats by jugular venepuncture under light ether anaesthesia before the treatments were started. At the end of the treatment periods, the 25-month-old rats were decapitated and blood samples were collected and processed as described above. Plasma LH, $\mathrm{FSH}$, prolactin, oestradiol and progesterone concentrations were measured.

\section{Radioimmunoassay of gonadotrophins and prolactin}

Plasma LH, FSH and prolactin concentrations were measured by specific radioimmunoassays using second antibody-facilitated separation and reagents kindly provided by the National Hormone and Pituitary Program (NIADDK, Bethesda, MD). The methods used have been described in detail by Tresguerres and Esquifino (1981), Esquifino et al. (1989) and Díaz et al. (1995).

\section{Radioimmunoassay of oestradiol and progesterone}

Plasma oestradiol and progesterone were measured by a ${ }^{125} \mathrm{I}$ radioimmunoassay kit using commercial ImmunoChem ${ }^{\mathrm{TM}}$ coated tubes, according to the manufacturers' instructions (ICN Pharmaceuticals, Inc., Costa Mesa, CA). The minimum amounts of oestradiol and progesterone significantly different from zero were $10 \mathrm{pg} \mathrm{ml}^{-1}$ and $0.15 \mathrm{ng} \mathrm{ml}^{-1}$, respectively. The assay maximal binding for oestradiol was $32.3 \%$, and the intra-assay coefficient of variation was $5.5 \%$. The maximal binding for progesterone was $50.1 \%$, and intra-assay coefficient of variation was $4.9 \%$.

\section{Statistical analysis}

Statistical analysis was performed using the SPSS (9.0) statistical program. Results were expressed as mean \pm SEM. Statistical analysis was performed using Mann-Whitney test for comparisons among groups studied at each time point, to compare the following pairs of interest: cyclic control versus acyclic control rats, cyclic melatonin-treated versus acyclic melatonin-treated rats, cyclic control versus cyclic melatonin-treated rats, and acyclic control versus acyclic melatonin-treated rats. Time-dependent changes in 
each group studied were compared using analysis of repeated measures using the statistical 'Hotelling trace'.

\section{Results}

\section{Pituitary responsiveness to $\mathrm{GnRH}$}

In all groups of rats studied (cyclic control, cyclic melatonin-treated, acyclic control and acyclic melatonintreated), a positive LH response $(P<0.01)$ was observed from 15 to $90 \mathrm{~min}$ after GnRH injection (Fig. 1). Comparisons between each time point demonstrated significantly higher $(P<0.05)$ LH values in the acyclic controls than in the acyclic melatonin-treated animals before and $90 \mathrm{~min}$ after administration of $\mathrm{GnRH}$.

There was no positive response in terms of FSH release after $\mathrm{GnRH}$ injection in any of the groups studied. However, between time points, age-dependent differences were observed. Before GnRH injection, significantly $(P<0.05)$ higher FSH concentrations were found in the acyclic controls compared with the cyclic control rats. At 30,60 and 90 min after GnRH injection, FSH concentrations were significantly higher $(P<0.01)$ in the acyclic control and the acyclic melatonintreated groups compared with the cyclic control and cyclic melatonin-treated rats. Only at $15 \mathrm{~min}$ after $\mathrm{GnRH}$ injection were differences owing to melatonin treatment observed, with significantly higher $(P<0.05)$ FSH concentrations in cyclic melatonin-treated compared with cyclic control rats.

Prolactin concentrations were not affected by $\mathrm{GnRH}$ treatment. However, differences among the groups were observed at the different time points. Prolactin concentrations were significantly higher $(P<0.01 ; P<0.05)$ in the acyclic controls compared with the cyclic controls before and 30 and 90 min after GnRH injection. In acyclic melatonin-treated rats, significantly higher $(P<0.01)$ prolactin concentrations compared with those in cyclic melatonin-treated rats were only observed before and $15 \mathrm{~min}$ after $\mathrm{GnRH}$ injection. An influence of melatonin on prolactin response to $\mathrm{GnRH}$ was only observed at the end of the test in cyclic rats, with cyclic melatonin-treated rats showing significantly higher prolactin concentrations $(P<0.01)$ than cyclic control rats.

\section{Plasma pituitary hormones}

LH concentrations in the acyclic control, 25-month-old rats were significantly higher $(P<0.05)$ than those observed in the acyclic control, 23-month-old rats (Fig. 2). Melatonin treatment for 2 months significantly reduced $(P<0.05) \mathrm{LH}$ concentrations in cyclic and acyclic rats. FSH concentrations in the 25-month-old acyclic control rats were significantly higher $(P<0.01)$ than in the 23 -month-old acyclic controls and in the 5-month-old cyclic control rats. Melatonin treatment did not modify FSH concentrations in the 5month-old cyclic control rats. However, significantly lower FSH concentrations $(P<0.01)$ were observed in the 25 month-old acyclic rats. Prolactin concentrations were significantly lower $(P<0.05)$ in the 25-month-old rats compared with the 23-month-old acyclic control rats.
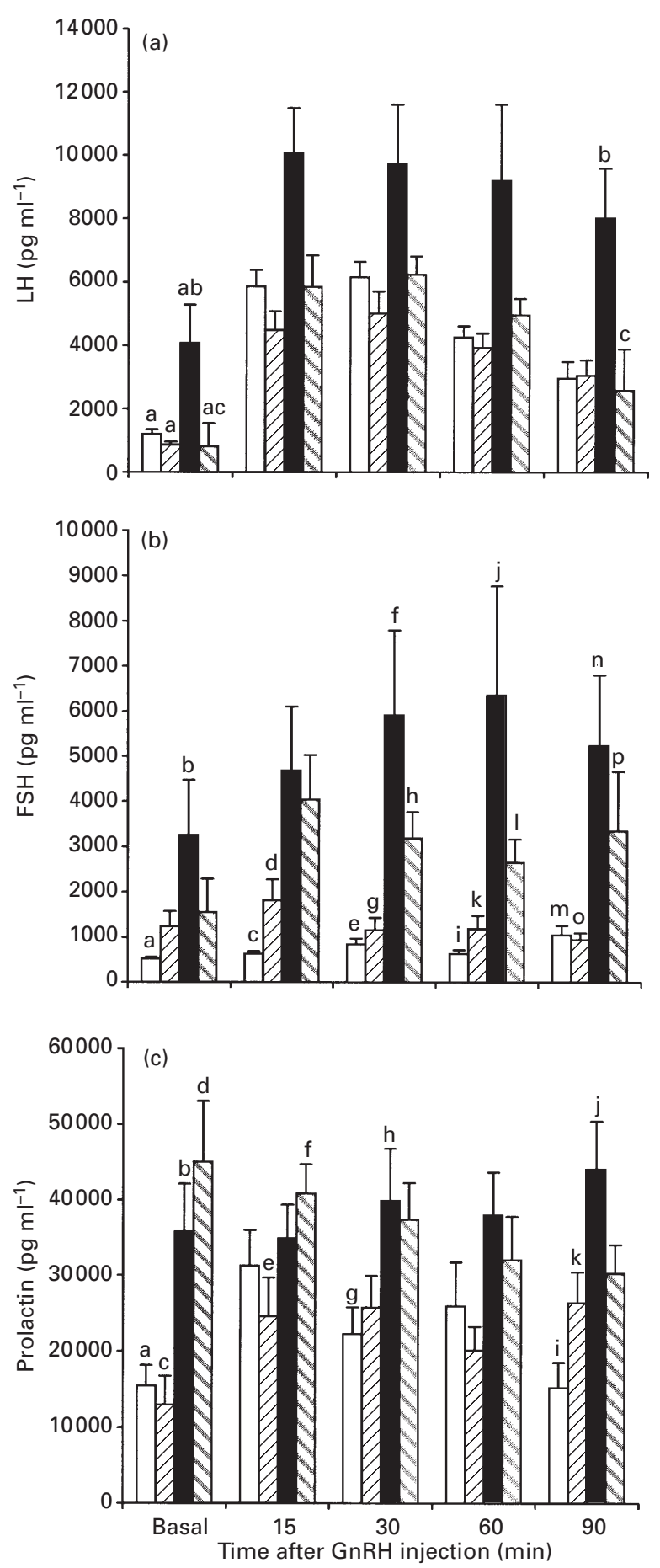

Fig. 1. Concentrations of plasma (a) LH, (b) FSH and (c) prolactin in cyclic and acyclic rats before and 15, 30,60 and $90 \mathrm{~min}$ after the injection of $50 \mathrm{ng} \mathrm{GnRH}$ per $100 \mathrm{~g}$ body weight to control and melatonin-treated rats $(150 \mu \mathrm{g}$ melatonin per $100 \mathrm{~g}$ body weight for 1 month). $\square$, Cyclic control rats; $\nabla$, cyclic melatonin-treated rats; $\mathbf{\square}$, acyclic control rats; $₫$, acyclic melatonin-treated rats. (a) Significant differences: a, $P<0.01$ compared with the same treatments at 15,30 , 60 and 90 min after GnRH; b versus c, $P<0.05$. (b) Significant differences: a versus $b$, c versus $d, P<0.05$; e versus $f$, $g$ versus $h$, $i$ versus $j$, $k$ versus $1, m$ versus $n$, o versus $p, P<0.01$. (c) Significant differences: a versus $b$, c versus $d$, e versus $f$, g versus $h$, i versus $j$, i versus $k$, $P<0.01$. 

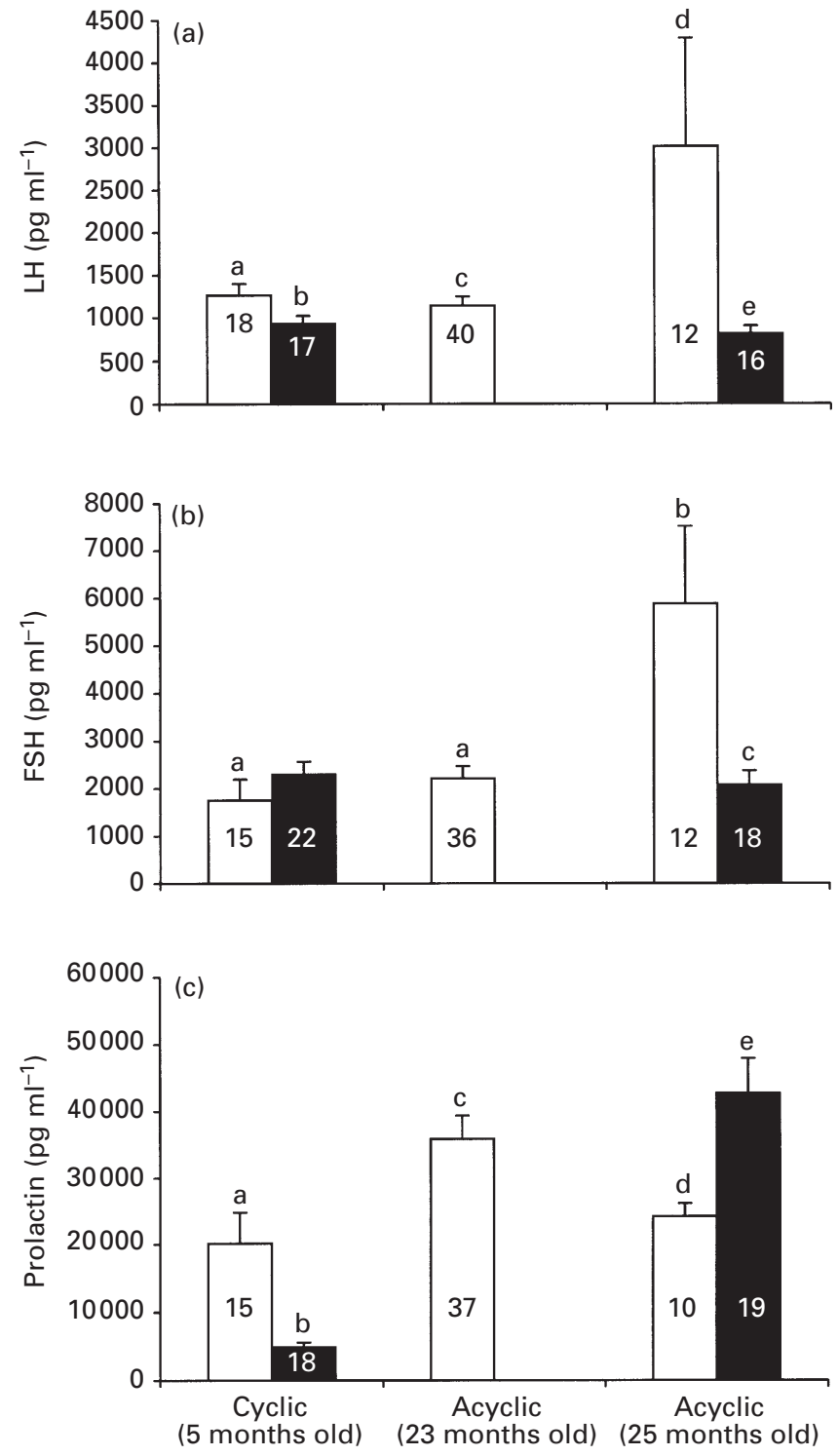

Fig. 2. Concentrations of (a) LH, (b) FSH and (c) prolactin in cyclic and acyclic control $(\square)$ and melatonin-treated rats $(\boldsymbol{\square}, 150 \mu \mathrm{g}$ per $100 \mathrm{~g}$ body weight for 2 months). Numbers within histograms represent the number of animals per group. (a) Significant differences: a versus $b, c$ versus $d, d$ versus $e, P<0.05$. (b) Significant differences: a versus $b, b$ versus $c, P<0.01$. (c) Significant differences: a versus $b, P<0.01$; c versus $d$, $d$ versus e, $P<0.05$.

Melatonin treatment significantly decreased prolactin concentrations $(P<0.01)$ in the cyclic rats, but significantly increased $(P<0.05)$ prolactin concentrations in the acyclic rats.

\section{Plasma ovarian hormones}

There were no differences in oestradiol or progesterone concentrations between the cyclic and acyclic control rats (Fig. 3). The lack of difference in oestradiol concentration
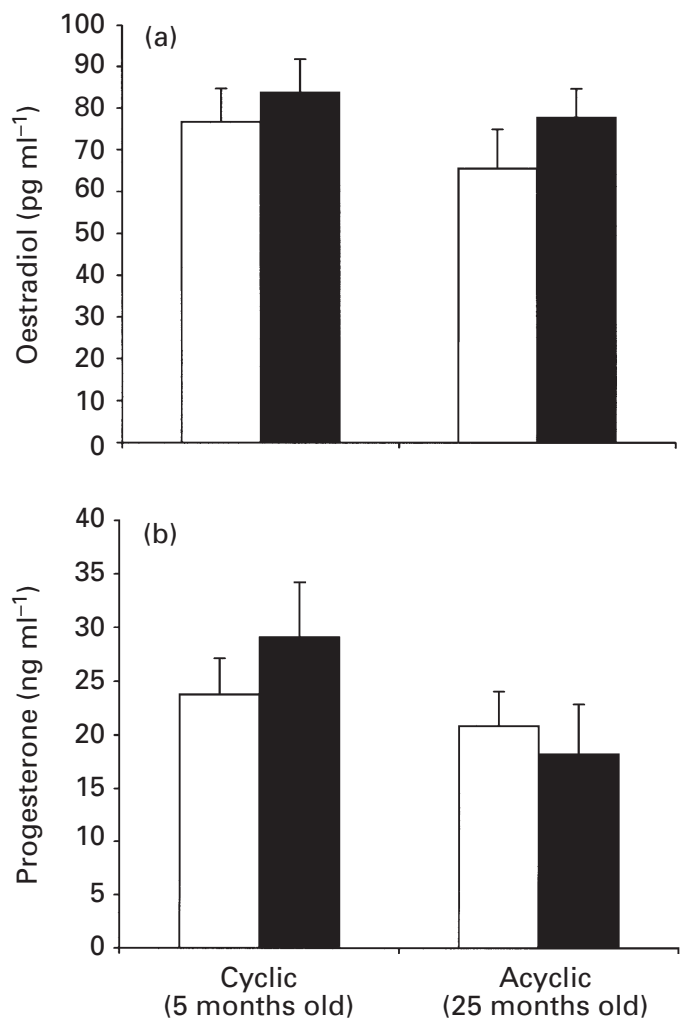

Fig. 3. Concentrations of (a) oestradiol and (b) progesterone in cyclic and acyclic control $(\square)$ and melatonin-treated rats $(\square, 150 \mu \mathrm{g}$ per $100 \mathrm{~g}$ body weight for 2 months).

between persistent oestrous and persistent dioestrous acyclic rats may be due to the instability of the persistent oestrous condition. Only $20 \%$ of the acyclic rats used in the present study showed persistent oestrus but vaginal smears taken over the 15 day period of study showed some of these rats to be in the dioestrous condition. No effect of melatonin treatment was observed on the steroid hormones studied in cyclic or acyclic rats.

\section{Discussion}

The results of the present study show a pituitary LH positive response to a bolus of GnRH in both cyclic and acyclic rats. The magnitude of the response was higher in acyclic than it was in the cyclic control rats, which indicates altered pituitary responsiveness to $\mathrm{GnRH}$ in old acyclic rats. An altered agedependent physiological response has been observed in pituitary studies in vitro of old rats in persistent oestrus, in which GnRH significantly increased LH release above basal concentrations in young and persistent oestrous rats, and the magnitude of the response was significantly lower in pituitaries from persistent oestrous rats (Jih and $\mathrm{Wu}, 1995)$. In addition, a smaller increase in serum LH after GnRH injection has been observed in aged compared with young rats in prooestrus, oestrus or at day 2 of dioestrus (Watkins et al., 1975). 
Results indicate that changes in the ability of the pituitary to release LH in older noncyclic female rats occurs as a consequence of the altered endocrine status of these animals and not as a direct result of chronological age (Cooper et al., 1984). In the present study, the young cyclic rats were at day 1 of dioestrus, when pituitary responsiveness to $\mathrm{GnRH}$ is lower (Smith et al., 1982) and, consequently, the magnitude of the positive response is lower in the young cyclic rats. In postmenopausal women, in whom mean $\mathrm{LH}$ and $\mathrm{FSH}$ concentrations did not change with chronological age, it was found that the LH pulse frequency decreased significantly and the response to GnRH increased (Lambalk et al., 1997). In ewes, Clarke and Cummins (1985) reported that, as the frequency of GnRH pulses decreases, the amplitude of the LH response increases.

The results of the present study indicate that administration of melatonin to young cyclic rats did not modify the pituitary responsiveness to GnRH. However, in old acyclic rats, melatonin treatment restored the response to the concentrations observed in young cyclic rats. These results indicate that melatonin may be involved in the pituitary responsiveness to $\mathrm{GnRH}$ during ageing and that melatonin administration may act upon the hypothalamo-pituitary axis to improve the $\mathrm{LH}$ response to $\mathrm{GnRH}$ during ageing. In support of this hypothesis, it had been demonstrated that a pineal-directed circadian function and cyclicity is fundamental for the regulation of sexual reproductive functions and that proper intervention with melatonin may postpone ageing of both neural and gonadal sexual function (Pierpaoli et al., 1997). Li et al. (1997) found that the decrease in GnRH gene expression, which is likely to be involved in the decline of reproductive function associated with ageing, can be completely reversed by short-term administration of melatonin, indicating that this hormone may be involved in the decrease of GnRH neuronal activity during ageing. No increase in FSH secretion was observed in response to GnRH injections, and there is considerable support for the hypothesis that one component of FSH secretion is independent of GnRH. Hall et al. (1988) demonstrated that when GnRH receptors were blocked by a GnRH antagonist in women, LH pulses and plasma concentrations were reduced. In contrast, FSH concentrations did not change. A marked asynchronicity between LH and FSH pulses was found in ovariectomized rats with clear LH but not FSH pulses after every injection of GnRH (Lambalk et al., 1988). The age-related loss of synchrony between LH and FSH pulses indicates a hidden FSHstimulating mechanism that drives FSH episodic release independently and more promptly than GnRH (Genazzani et al., 1997). Although no prolactin response to $\mathrm{GnRH}$ was observed in the present study, melatonin treatment slightly affected prolactin concentrations in acyclic rats, decreasing these concentrations to amounts similar to those observed in young cyclic control rats at the end of the test. Dopamine, through its inhibitory action, appears to control prolactin secretion (Thyagarajan et al., 1995). Dopamine activity from adulthood through middle-age to senescence shows marked reductions at old age (22-24 months of age) (Mohankumar et al., 1994). This age coincides with the age (24-month-old) in which the GnRH test was performed in acyclic rats and may explain the significantly higher basal prolactin values observed in both acyclic control and melatonin treated groups compared with their respective cyclic groups.

The chronological pattern of gonadotrophins and prolactin indicate that an important change in secretory processes occurs from 23- to 25-month-old rats, with gonadotrophins increasing while prolactin decreases. In addition, the increase in serum FSH that accompanies female reproductive ageing may occur before changes in oestradiol concentration. The decrease in inhibin B also precedes the decrease in inhibin A and occurs in concert with an increase in oestradiol, indicating that inhibin B negative feedback is the most important factor controlling the early increase in FSH with ageing (Welt et al., 1999). These mechanisms may explain the increased basal FSH concentrations that occur without significant differences in basal oestradiol or progesterone concentrations in 23-25month-old acyclic control rats compared with cyclic control rats at the dioestrous phase of the sexual cycle. It is likely that no differences in prolactin concentration were observed between acyclic control (25-month-old) rats and cyclic control (5-month-old) rats because of the low prolactin concentrations that occur during the dioestrous phase of the sexual cycle in cyclic rats (Mohankumar et al., 1994). The increased prolactin concentrations observed in acyclic control (24-month-old) rats may be due to method of extraction used, as the stress of ether anaesthesia has been reported to affect prolactin release (Wiggins et al., 1983). However, in rats at 25 months of age, non-stressed prolactin concentrations were obtained from blood drawn by decapitation. The results obtained from acyclic melatonin-treated rats under the same blood drawing procedures indicate increased prolactin concentrations that are independent of the stressful procedure. Melatonin treatment produces an age-dependent effect on prolactin concentrations since, in young cyclic rats, melatonin resulted in reduced prolactin concentrations. However, the opposite effect was found in the old acyclic rats.

In summary, the results of the present study indicate that ageing increases gonadotrophin release but only affects GnRH-stimulated LH release. Melatonin treatment during ageing restores pituitary responsiveness, showing a similar response to that in young cyclic rats. During ageing, gonadotrophin but not ovarian hormone concentrations after melatonin treatment were decreased, providing evidence that the influence of melatonin is exerted mainly at the hypothalamo-pituitary axis rather than upon the ovary, at least when the ovary is at a quiescent stage.

The authors wish to express their gratitude to the NIADDK, NHPP and to A. F. Parlow for the supply of radioimmunoassay materials for $\mathrm{LH}, \mathrm{FSH}$ and prolactin radioimmunoassays. This work has been supported for the Spanish Ministry of Health, Fondo de Investigación Sanitaria; FIS number 97/0988. And to D. Skenne for her grammatical assistance in preparing the manuscript. And to the Statistics Department of The University of Oviedo, Spain.

\section{References}

Brito AN, Sayles TE, Krieg RJ, Jr and Matt DW (1994) Relation of attenuated proestrus luteinizing hormone surges in middle-aged female rats to in vitro pituitary gonadotropin-releasing hormone responsiveness Euopean Journal of Endocrinology 130 540-544 
Clarke IJ and Cummins JT (1985) GnRH pulse frequency determines LH pulse amplitude by altering the amount of releasable $\mathrm{LH}$ in the pituitary glands of ewes Journal of Reproduction and Fertility 73 425-431

Cooper RL, Roberts B, Rogers DC, Seay SG and Conn PM (1984) Endocrine status versus chronologic age as predictors of altered luteinizing hormone secretion in the 'aging' rat Endocrinology 114 391-396

Díaz López B, Colmenero Urquijo MD, Díaz Rodríguez ME, Arce Fraguas A, Esquifino Parras AI and Marín Fernández B (1995) Effect of pinealectomy and melatonin treatment during pregnancy on the sexual development of the female and male rat offspring European Journal of Endocrinology 132 765-770

Esquifino AI, Villanúa MA, Agrasal C and Tresguerres JAF (1989) Possible prolactin-mediated effects of melatonin on gonadotropin secretion in the rat Pharmacology Biochemistry and Behaviour 32 157-162

Genazzani AD, Petraglia F, Sgarbi L, Montanini V, Hartmann B, Surico N, Biolcati A, Volpe A and Genazzani AR (1997) Difference of LH and FSH secretory characteristics and degree of concordance between postmenopausal and ageing woman Maturitas 26 133-138

Glass JD and Knotts LK (1987) A brain site for the antigonadal action of melatonin in the white footed mouse (Peromyscus leucopus): involvement of the immunoreactive GnRH neuronal system Neuroendocrinology 46 48-55

Gorni RC, Pereira EP, Cipola-Neto J and Pekelmann R (1993) Age-related changes in melatonin modulation of sympathetic neurotransmission Journal of Pharmacology and Experimental Therapy 266 1536-1540

Hall JE, Brodie TD, Badger TM, Rivier J, Vale W, Conn PM, Schoenfeld D, Crowley WF, Jr (1988) Evidence of differential control of FSH and LH secretion by gonadotropin-releasing hormone $(\mathrm{GnRH})$ from the use of a GnRH antagonist Journal of Clinical Endocrinology and Metabolism 67 524-531

Hofmann GE, Scott RT, Horowitz GM, Thie J and Navot D (1995). Evaluation of the reproductive performance of women with elevated day 10 progesterone levels during ovarian reserve screening Fertility and Sterility 63 979-983

Jih MH and Wu TC (1995) Altered regulation of pituitary luteinizing hormone secretion by $\mathrm{GnRH}$ and inhibin in aged persistent-estrous female rat Mechanism of Ageing and Development 29 15-27

Lambalk CB, van Rees GP, Schoemaker J, de Koning J and van Dieten JA (1988) Pulsatile GnRH treatment of the ovariectomized rat and release of LH and FSH Acta Endocinologica (Copenhagen) 119 27-32

Lambalk CB, de Boer L, Schoute E, Popp-Snyders C and Schoemaker J (1997) Post-menopausal and chronological age have divergent effects on pituitary and hypothalamic function in episodic gonadotrophin secretion Clinical Endocrinology 46 439-443

Li S, Givalois L and Pelletier G (1997) Effects of ageing and melatonin administration on gonadotropin-releasing hormones (GnRH) gene expression in the male and female rat Peptides 18 1023-1028

Matt DW, Gilson MP, Sales TE, Krieg RJ, Kerbeshian MC, Veldhuis JD and Evans WS (1998) Characterization of attenuated proestrus luteinizing hormone surges in middle-aged rats by deconvolution analysis Biology of Reproduction 59 1477-1482

Mohankumar PS, Thyagarajan S and Quadri SK (1994) Correlations of catecholamine release in the medial preoptic area with proestrus surges of luteinizing hormone and prolactin: effects of aging Endocrinology 135 119-126

Navot D, Drews MR, Bergh PA, Guzman I, Karstaedt A and Scott RJ, Jr (1994) Age-related decline in female fertility is not due to diminished capacity of the uterus to sustain embryo implantation Fertility and Sterility 61 97-101

Oaknin-Bendahan S, Anis Y, Nir I and Zisapel N (1995) Effects of long-term administration of melatonin and a putative antogonist on the ageing rat Neuroreport 6 785-788

Pierpaoli W, Bulian D, Dall'Ara A, Marchetti B, Gallo F, Morale MC, Tirolo C and Testa N (1997) Circadian melatonin and young-to-old pineal grafting postpone ageing and maintain juvenile conditions of reproductive functions in mice and rats Experimental Gerontology 32 587-602

Rasmussen DD, Boldt BM, Wilkinson CW, Yellon SM and Matsumoto AM (1999) Daily melatonin administration at middle age suppresses male rat visceral fat, plasma leptin, and plasma insulin to youthful levels Endocrinology 140 1009-1012

Reiter RJ (1992) The ageing pineal gland and its physiological consequences BioEssays 14 169-175

Scarbrough K and Wise PM (1990) Age-related changes in pulsatile luteinizing hormone release precede the transition to estrous acyclicity and depend upon estrous cycle history Endocrinology 126 884-890

Smith WA, Cooper RL and Conn PM (1982) Altered pituitary responsiveness to gonadotropin-releasing hormone in middle-aged rats with 4-day estrous cycles Endocrinology 111 1843-1848

Thyagarajan S, Mohankumar PS and Quadri SK (1995) Cyclic changes in the release of norepinephrine and dopamine in the medial basal hypothalmus: effects of ageing Brain Research 14 122-128

Tresguerres JAF and Esquifino AI (1981) Dissociation in LH and FSH regulation in a hyperprolactinaemic model: interrelationship between gonadotropin and prolactin control Journal of Endocrinology 90 41-51

Waldhauser F and Steger H (1986) Changes in melatonin secretion with age and pubescence Journal of Neural Transmission 21 183-197

Watkins BE, Meites J and Riegle GD (1975) Age-related changes in pituitary responsiveness to GnRH in the female rat Endocrinology 97 543-548

Welt CK, McNicholl DJ, Taylor AE and Hall JE (1999) Female reproductive ageing is marked by decreased secretion of dimeric inhibin Journal of Clinical Endocrinology and Metabolism 84 105-111

Wiggins C, Ratner A, Wise PM (1983) Differences in the stress response of prolactin in young and aged female rats Life Sciences 32 1911-1917

Zisapel N, Shaharabani M and Laudon M (1987) Regulation of melatonin's activity in the female rat brain by estradiol: effects on neurotransmitter release and on yodo-melatonin binding sites Neuroendocrinology 46 207-216 